\title{
ADOLFO LEÓN GÓMEZ Y EL PRESIDIO EN EL PRIMER CUARTO DEL SIGLO XX EN COLOMBIA ${ }^{1}$
}

\author{
Ricardo Garzón Cárdenas \\ Instituto Latinoamericano de Altos Estudios-ILAE
}

\section{Resumen}

El presente trabajo es un recorrido por las dos obras que escribió Adolfo León Gómez, Secretos del Panóptico y La ciudad del dolor: ecos del presidio de inocentes, relacionadas con dos conceptos básicos de la Criminología que, muchas décadas después, adquirieron una gran relevancia en la disciplina: la naturaleza política de la pena y el presidio terapéutico como forma de control social. Este trabajo también es un referente para analizar la evolución de los derechos de los presos ante el castigo estatal.

Palabras clave: Adolfo León Gómez, Criminología, presidio político, presidio terapéutico.

El autor: abogado, doctorando en Derecho. Director de Procesos del Instituto Latinoamericano de Altos Estudios-ILAE.

Recibido: 28 de noviembre de 2016; evaluado: 1 de diciembre de 2016; aceptado: 5 de diciembre de 2016.

\footnotetext{
La primera referencia a este personaje la encontré en el estudio de Germán Silva García, Criminología: Construcciones sociales e innovaciones teóricas (Bogotá: Instituto Latinoamericano de Altos Estudios, 2011). De este mismo investigador, en una conversación informal, surgió la invitación a profundizar sobre el pensamiento criminológico de este desconocido personaje. Por estas dos razones, este trabajo, si bien enteramente personal, nunca hubiera visto la luz sin el entusiasmo y los trabajos previos del doctor Silva García, por lo que le doy un expreso agradecimiento. Un pequeño resumen de este trabajo había sido publicado como "Pensador latinoamericano destacado: Adolfo León Gómez", en la revista Nuevos paradigmas de las Ciencias Sociales latinoamericanas y puede verse en http://www.ilae.edu.co/Publicaciones/files/07.\%20Pensador\%20 destacado\%20IV-7.pdf

Este trabajo es parte del proyecto de investigación DER2016-74898-C2-1-R, "Conflictos de derechos, tipologías, razonamientos, decisiones", del Ministerio de Economía y competitividad del Gobierno español.
} 


\title{
ADOLFO LEÓN GÓMEZ AND INCARCERATION IN THE FIRST QUARTER OF THE $20^{\text {th }}$ CENTURY IN COLOMBIA
}

\author{
Ricardo Garzón Cárdenas \\ Instituto Latinoamericano de Altos Estudios-ILAE
}

\begin{abstract}
The present work reviews two works written by Adolfo León Gómez, Secretos del Panóptico (Secrets of the Panopticon) and La ciudad del dolor: ecos del presidio de inocentes (The city of pain: Echoes of the incarceration of innocents), related to two basic concepts of criminology that, many decades later, acquired great relevance in the discipline: the political nature of punishment and therapeutic incarceration as a form of social control. They are also a reference work to analyze the evolution of the rights of prisoners in the face of state punishment.
\end{abstract}

Keywords: Adolfo León Gómez, criminology, political incarceration, therapeutic incarceration.

About the author: Lawyer, PhD student in Law. Director of Processes at the Instituto Latinoamericano de Altos Estudios-ILAE.

Received: November 28, 2016; evaluated: December 1, 2016; accepted: December 5, 2016. 
Todo cuanto se haga por hacer conocer del público [las iniquidades], que en general las ignora, para que abominándolas desde luego, trabaje porque se corrijan cuanto antes y se eviten totalmente en lo futuro, será prestar un eficaz servicio a la Nación entera. ${ }^{2}$

Quizás el primero de los criminólogos colombianos se convirtió en tal por haber portado hasta su muerte la condición de preso. Se trata de Adolfo León Gómez, un cundinamarqués que dejó para la posteridad un retrato vívido del presidio político y del sanitario. Su primera narración corresponde a su tercera reclusión en el Panóptico Central, construcción en la que hoy se ubica el Museo Nacional de Colombia (Bogotá); la segunda se refiere a su confinamiento, casi dos décadas después y hasta su muerte, en el Lazareto ${ }^{3}$ o Leprosorio de Agua de Dios (Cundinamarca).

Adolfo León Gómez nació el 19 de septiembre de 1857 en Pasca (Cundinamarca) ${ }^{4}$ y murió el 9 de junio de 1927 en Agua de Dios. Fue un abogado, escritor, periodista y político que tuvo en su hoja de vida el haber sido senador, magistrado de la Corte Suprema de Justicia, fundador de la Academia Colombiana de Jurisprudencia y presidente de la Academia Colombiana de Historia. Su pensamiento y activismo liberal lo llevaron a participar en las varias guerras civiles entre liberales y conservadores que se presentaron entre los siglos XIX y XX, ${ }^{5}$ por cuenta de las cuales fue

Adolfo León Gómez, Secretos del Panóptico (Bogotá: Imprenta de M. Rivas, 1905), 1.

El término "lazareto" viene ligado al término "mal de san Lázaro", nombre que ha tenido la enfermedad por asociación al personaje bíblico resucitado por Jesús, de quien se cree sufrió de lepra. En virtud de este, los enfermos también han sido llamados lazarinos. Hugo Armando Sotomayor Tribín, "Historia de la lepra en Colombia", http://www.sanatorioaguadedios.gov.co/documentos/histolepracolombia.pdf (acceso febrero 25, 2012).

4 Un dato histórico de interés es su ascendencia. Fue bisnieto de José Acevedo y Gómez, el Tribuno del Pueblo y nieto de María Josefa Acevedo de Gómez, la primera mujer poeta de la República. Para mayor información sobre los datos biográficos de León Gómez, se puede revisar la muy completa investigación de Alfredo Molano Jimeno, "Adolfo León Gómez, el desterrado (1858-1927)" (tesis de pregrado, Pontificia Universidad Javeriana, 2015).

5 Tras la promulgación de la Constitución de 1886, vino un período de hegemonía conservadora conocido como la Regeneración. Se caracterizó por el desmonte del sistema federal, un rígido centralismo político, la injerencia de la Iglesia en los asuntos públicos y la persecución de los activistas liberales. Producto de la represión, los liberales se levantaron en armas varias veces, sin mayor éxito militar; de estas refriegas, la más importante y sangrienta se presentó entre 1899 y 1902 y fue conocida como la Guerra de los mil días. Aunque hay historiadores que dudan de la cifra y al parecer no se ha podido validar el dato, se dice que en esta guerra las bajas fueron de cien mil, en una época en la que esta cantidad constituía 2,5\% de la población del país. David Bushnell, Colombia, una Nación a pesar de sí misma, trad. Claudia Montilla (Bogotá: Planeta, 2007), 219. Para un análisis pormenorizado de esta guerra, véase Javier Ocampo López, Colombia en sus ideas. T. II (Bogotá: Universidad Central, 1999). 
apresado varias veces; la reclusión más dura fue la tercera, aquella que retrató en su libro Secretos del Panóptico, de 1903.

El propósito de esta obra es claramente histórico y político, pues se propuso "conservar la memoria y [...] enaltecer el mérito de tantos distinguidos y valerosos caballeros que lograron fugarse del Panóptico o afrontar sus más terribles horrores por largo tiempo". ${ }^{6}$ Seguido, comenta cómo pretendía, mediante una censura moral y un juicio histórico, hacer graves denuncias:

[...] y a servir de sanción, aunque benigna, contra los que abusando de su autoridad y confundiendo la energía con la dureza terca, fueron crueles hasta el exceso, no sólo con los revolucionarios sino con personas inofensivas de quienes querían vengarse. $^{7}$

Más que un relato autobiográfico, Secretos del Panóptico es un conjunto de reflexiones agudas respecto a lo que la cárcel pretende con los individuos, la selección preferente del sistema penal de aquellas personas que impugnan la legitimidad del poder político imperante, las inexistentes garantías al debido proceso y el trato deshumanizado en ella. Narra en el primer capítulo:

El 13 de octubre de 1900 fui encarcelado por tercera vez durante la última guerra civil, por orden del Jefe Civil y Militar de Cundinamarca, General Arístides Fernández, y por pretextos políticos. Como en las ocasiones anteriores, me llevaron sin oírme, sin hacerme cargo alguno, sin explicarme la causa, la denuncia o la sospecha. ${ }^{8}$

Luego, hace una primera observación sociológica, en la que repara por su condición de recluso y resalta cómo el poder penal no es más que un mecanismo de persecución de los operadores hacia quienes se tiene animadversión:

Así entraban todos y así salían luego: sin que se les dijese nunca por qué. El capricho, la antipatía, el odio y las venganzas privadas de multitud de regeneradores que aprovechaban la oportunidad, eran la verdadera causa de muchas de las prisiones políticas. ${ }^{9}$

6 Este papel de conservación se lo tomó tan en serio, que el capítulo XXIII de la obra fue titulado "Nómina" y en él incorporaba los nombres de todos los presos del lugar.

León Gómez, Secretos del Panóptico, 2.

8 León Gómez, Secretos del Panóptico, 5.

9 León Gómez, Secretos del Panóptico, 7. 
Echa mano de sus habilidades literarias para hacer una descripción viva y detallada de la cárcel a donde llegó: la suciedad, la hediondez, el frío, la falta de intimidad, la desprotección ante sinnúmero de enfermedades y la disposición de las celdas, de tal manera que pudiera doblar la voluntad de los presos, fueron algunos de los aspectos que aparecen en sus narraciones y que aquí citamos in extenso:

Se compone ese local de un patio sucio, largo, mal enladrillado y sumamente húmedo, en cuyo extremo norte está la alberca, en ese entonces casi siempre seca; y en el costado occidental, al pie del inmenso paredón que da a la calle, al excusado, que no era otra cosa que un agujero enrejado de hierro sobre el hediondísimo caño de desagües del edificio, y medio oculto por dos de sus lados por un montón de baldosas puestas unas sobre otras. Por el lado norte y por encima, ese foco de infección estaba completamente descubierto, de modo que el que allí se colocaba era visto de todos los habitantes del local, y tenía encima las inclemencias del cielo, y debajo el infecto vapor de tifus, viruelas, disenterías y demás miasmas de muerte que pueblan el Panóptico. ${ }^{10}$

Esa humanidad impenetrable de la que hablaran otros literatos con ocasión del presidio en campos de concentración es protagonista esencial en la narración de León Gómez, en donde el recluso no puede ser despojado de ese algo inasible que algunos llaman alma o conciencia, así los verdugos se esforzaran. No todo era malo. El hecho de haber agrupado los disidentes políticos más notables se prestó para exquisitas tertulias y la reflexión libre de esos cuerpos presos.

León cuenta cómo el periodista José M. Pérez Sarmiento no pudo ser despojado de su oficio: "El estimable amigo José M. Pérez Sarmiento, siempre alegre, siempre entusiasta y sobre todo siempre periodista, fundó un periódico manuscrito en que se escribieron buenos artículos. Abel Camacho daba clases de inglés". ${ }^{11}$ A su lado estuvo también el eximio poeta Julio Flórez, con quien se hicieron veladas literarias en compañía de otros escritores. ${ }^{12}$

En el capítulo sexto, titulado "La inquisición", hace una descripción de los castigos que se suministraban en la cárcel y cuya narración es un instrumento invaluable para la reconstrucción de la historia criminológica colombiana. Empieza describiendo el cepo, conocido en muchos otros lugares:

\footnotetext{
León Gómez, Secretos del Panóptico, 8.

León Gómez, Secretos del Panóptico, 19-20.

12 León Gómez, Secretos del Panóptico, 27.
} 
[...] un suplicio tan bárbaro, que aun a los hombres más esforzados y valientes hacía gritar y llorar [...] consistía en dos maderos paralelos colocados horizontalmente sobre dos postes verticales a cierta altura del suelo. En esos maderos había agujeros para meter los pies del preso, que quedaba colgando con la cabeza contra los ladrillos. ${ }^{13}$

También habló de la picota:

Esta es un botalón o poste de hierro clavado en la mitad de un patio, a flor de tierra. De la cabeza de ese poste salen tres gruesas cadenas de hierro, y una de éstas la remachaba un herrero sobre el tobillo del preso, que permanecía allí, según su falta o la crueldad de sus verdugos, un día o dos, o tres o más, con sus noches, a la intemperie, girando alrededor del poste con desesperación horrible y satisfaciendo en el mismo lugar sus necesidades corporales. ${ }^{14}$

Asimismo comentó el mico, que consistía en atar el preso a una cadena de hierro que tenía en el otro extremo un tronco de madera; con tal lastre, el paciente, en palabras de León, se veía obligado a cargar el peso como si se tratara de un niño en brazos. ${ }^{15}$ Aunque advierte que de este castigo le contaron, pues no lo vio, el relato no solo es creíble, sino que es evidencia de la honestidad intelectual de este hombre que estaba en unas condiciones en las que no le era exigible tal objetividad.

Adicionalmente, León menciona lo que a sus ojos era el castigo más duro, aquel vinculado con el honor de los caballeros que allí se encontraban presos. En un testimonio de los valores de su tiempo y de la dignidad que se consideraba más alta, comenta cómo sufrió, en persona y por solidaridad, por la privación de objetos de alta afección:

Jamás en mi vida me sentí tan humillado como cuando los esbirros de la Regeneración, que me quitaron de mi oficina mi máquina de escribir y mi revólver, y de la casa una montura aperada y otros valores, esculcaban en público mis bolsillos en busca de un reloj y la cartera que robaron a mi hermano Anselmo y otras cosas que perdieron diversos individuos. Jamás en mi vida odié más estas infames guerras de partido como cuando presencié la misma afrenta, hecha ante tanta gente, a caballeros tan honorables como los que allí había [... ${ }^{16}$

León Gómez, Secretos del Panóptico, 78.

León Gómez, Secretos del Panóptico, 78-80.

León Gómez, Secretos del Panóptico, 78-80.

León Gómez, Secretos del Panóptico, 93. 
Es de anotar sobre esta obra el fino humor negro de León Gómez, quien cuenta cómo los policías de guardia irrumpieron en las celdas para robar todas las botellas que tenían los reclusos para el agua o cualquier líquido, en razón a la subida del precio de las botellas en la cervecería Bavaria. Exclama: "¡Oh policía!" ${ }^{17} \mathrm{La}$ detención de León Gómez se prolongó, tal vez, hasta la terminación de la guerra, mediante Decreto 638 de 1 de junio de 1903.

\section{II}

Si Secretos del Panóptico fue una contribución al entendimiento del presidio político en Colombia, su otra obra se encargó de presos de otro tipo. El evocador título basta para imaginar el relato que contiene: su nombre fue La ciudad del dolor: ecos del presidio de inocentes, de 1923.

León Gómez tuvo el infortunio de padecer lepra, fuente de pánico ante el contagio y una plaga bíblica en un país altamente confesional. ${ }^{18}$ El miedo a la enfermedad había motivado la construcción de colonias que, bajo el discurso terapéutico, constituían prisiones vitalicias.

La "ciudad del dolor" de León Gómez fue el leprosorio de Agua de Dios, fundado en 1871, lugar en el que murió en las condiciones indignas propias de los estigmatizados en razón a esta enfermedad. La dureza de las condiciones eran de oído sabidas por él, lo que motivó una estancia solitaria en una casa de campo en Tocaima como preparación para el aislamiento de lo que le quedaba de vida. Dijo:

[...] para ir acostumbrándome poco a poco a la idea de ingresar al Lazareto $\mathrm{y}$, sobre todo, para no causar a mis hijos de improviso inmensa pena con la noticia de haber caído allí, no obstante la decidida oposición de todos ellos. ${ }^{19}$

17 León Gómez, Secretos del Panóptico, 94.

18 A pesar de que el mismo León Gómez estuvo seguro de haber padecido dicha enfermedad, hoy existe una hipótesis distinta. Efraím Otero Ruíz, historiador y médico de formación, además de nieto político de León Gómez, sostiene que no existe prueba alguna de que este personaje hubiera sufrido de lepra. Más bien, afirma que esta fue una manera que encontraron sus enemigos de excluirlo del escenario político. Según este autor, de lo que sí hay evidencia creíble es de que sufría de trastorno bipolar. Efraím Otero Ruíz, "Adolfo León Gómez (1858-1927), republicano, poeta y mártir", Boletín de Historia y Antigüedades XCIX, núm. 855 (2012): 353-376. En un sentido similar, Carlona Melo Rivera, "La enfermedad del horror y el olvido. El caso de Adolfo León Gómez", Salud, Historia, Sanidad 9, núm. 2 (2014): 117-150.

19 Adolfo León Gómez, La ciudad del dolor: ecos del presidio de inocentes (Bogotá: Imprenta M. Rivas, 1923), 11. 
En el escalofriante capítulo III, llamado "Descendí a los infiernos", cuenta la desazón que le produjo y la templanza que requirió cuando vio el sitio de reclusión:

[...] nadie en la vida ha llegado a la ciudad enferma con más horror, más miedo, más repugnancia, más compasión y más tristeza que yo, ni nadie que haya sufrido con mayor intensidad al penetrar por primera vez en su temeroso cerco de alambre erizado. Dios me recompensó aquel heroico sacrificio, dándome la fuerza con que año y medio después ya penetraba impávido a los antros más horribles y me familiarizaba con el dolor humano en sus formas supremamente aterradoras. ${ }^{20}$

Una vez más, como ocurriera con su otra obra, León Gómez pasó lentamente de la biografía y la reflexión personal a un análisis de mayor calado. Empieza a describir el castigo más fuerte que implicaba la reclusión: el olvido. Cuenta con tristeza que su enfermedad vergonzante había alejado a casi todos aquellos que posaban de ser sus amigos, colegas, discípulos o copartidarios. Algunas cartas que recibió eran precisamente para marcar distancia. Le escribieron "una sola carta de pesar y de eterna despedida, temerosos sin duda de recibir la 'peligrosa' correspondencia de un enfermo, porque ante el miedo y el prejuicio de nada sirve el autoclave". ${ }^{21}$

Una de las notables excepciones a ese trato desesperanzador fue la actitud asumida por la Academia Nacional de Historia, buena responsable de que su memoria no hubiera muerto con él en el leprosorio. Además de aprobar y difundir una proposición a favor de su antiguo presidente, ordenó la edición de varias de sus obras para ayudarlo económicamente en su penosa reclusión. ${ }^{22}$ Adicionalmente, cuenta

20 León Gómez, La ciudad del dolor, 15.

21 León Gómez, La ciudad del dolor, 21-22.

22 León Gómez, La ciudad del dolor, 81. Entre las publicaciones realizadas en virtud de la proposición, destaca una serie de poemas como "La amistad", que vale la pena citar completa:

DETENTE, Amistad, detente.

- Voy de prisa, voy de paso, en un banquete me esperan, tiempo hace, los convidados.

- Aguarda, Amistad, aguarda,

entra á descansar un rato.

— ¡Sí que hace frío en tu puerta,

sí que está tu rostro pálido!

¡Es tan triste tu morada

como el triste desengaño!...

Apenas tinta un perro

sobre el carbón apagado...

-Entra, Amistad, que sólo hallas

en este hogar solitario

a mi eterna compañera. 
la gratitud que sintió hacia su contradictor el general Rafael Reyes por haberle obsequiado un libro. ${ }^{23}$

El dolor era el mecanismo de normalización en este piadoso y terapéutico encierro. Las autoridades no tenían que esmerarse mucho en producirlo, pues la enfermedad, el clima con todos sus ávidos insectos y el abandono de los pacientes eran una mezcla efectiva para conseguir tal fin. En "La vía dolorosa", nombre del capítulo, narra el desfile que cada ocho días hacían aquellos leprosos cazados por los alcaldes y de baja clase social, que llegaban desde la estación del tren hasta el lugar de confinamiento. Dice:

Son los condenados por la sociedad, aterrada por el ponderado contagio, que no teme de otros males, a presidio perpetuo, lejos del hogar, de la familia y del mundo. Son los parias y los desheredados de la vida, marcados para siempre con un baldón más oprobioso que el del crimen. Son los muertos que lloran y sufren. ${ }^{24}$

El terror no provenía solo de ver llegar a estas pobres personas, sino de las condiciones en las que lo hacían:

Bajo un sol de fuego que calcina el cerebro, con una sed devoradora, con dolores en el cuerpo que acrecientan la tortura del alma, por un camino desierto, cuya arena asoleada quema los pies, y entre una escolta de polizontes, avanza la caravana infernal [...]. Nada más triste y más horrible que ver avanzar por

— ¡Cómo es de helada su mano,

cómo es su faz de sombría,

envuelta entre sus harapos!

Dime su nombre..

-Miseria.

—Adiós amigo, me marcho:

Donde la Miseria vive

la Amistad no tiene campo...

¡Sí que está triste mi alma,

sí que está mi rostro pálido!...

¡Cómo tinta mi perro

sobre el carbón apagado!...”. José María Rivas Groot, comp., La lira nueva (Bogotá: Instituto Caro y Cuervo, 1993), 173.

23 Dice: "[Él] olvidando gallardamente toda queja contra el único periodista de oposición a su gobierno, me envió un magnífico libro y una carta tan bella como su magnánimo corazón”. León Gómez, La ciudad del dolor, 104-105. La triste ironía en este acto de deferencia epistolar es que fue precisamente Rafael Reyes quien ordenó controlar los lazaretos, militarizarlos, ponerles alambres de púas y todas las medidas de separación entre los leprosos y sus familias. La motivación principal de estas acciones era dar garantías a los inversores extranjeros de que no serían contaminados con esta enfermedad. Diana Obregón, Batallas contra la lepra: Estado, Medicina y ciencia en Colombia (Medellín: Banco de la República-Eafit, 2002).

24 León Gómez, La ciudad del dolor, 140. 
aquel camino desolado mujeres, ancianos y niños enfermos agonizando de fatiga, sin que haya nadie que les ofrezca un pan o un vaso de agua, y que antes bien suelen ser maltratados, insultados y amenazados cuando se atreven a acercarse a alguna casucha a pedir un auxilio. ${ }^{25}$

Al descubrir el sanatorio como lo que luego Foucault llamó las instituciones de control total, León Gómez explicita cómo entre las alambradas se perdía la libertad y la condición de ciudadano. A cambio de la esperanza de la cura y de 30 centavos de peso diarios, fue anotado en la lista de las personas que, en sus palabras, entregaban sus derechos civiles y sociales. Se lamenta: "[...] quedé matriculado y herrado con el fierro candente e indeleble del leprosorio". ${ }^{26}$

La ilusión de cura, además de ser un tormento en sí, por lo que implicaba emocionalmente el anuncio de un tratamiento infalible y la exposición a los estafadores, era la excusa para que los pacientes sirvieran como medios de experimentación. Recuerda el tratamiento de un hospital cuyos médicos los pusieron en fila, sin importar la edad o el grado de avance de la enfermedad y, sin examen previo alguno, empezaron a inyectarles el ginocordato, con la misma aguja "ya roma y sangrienta" en las venas hasta obstruirlas. Este malévolo procedimiento fue, en retrospectiva irónica, desacreditado en su cientificidad por parte de León Gómez, quien supo:

[...] según informe escrito que envió el doctor Montaña de Bogotá al señor Evaristo Quijano, que el polvo, disuelto quién sabe cómo, que nos estaban introduciendo por las venas, era el que debíamos tomarnos por la boca a falta de las tabletas que el tratamiento prescribía y que los leprólogos de Agua de Dios no conocían aún [...]. De modo que al que no tenía la enfermedad, allí se la suministraban de otros brazos y al que la tenía, fácil era que le proporcionaran otra por añadidura. ${ }^{27}$

A esta indignidad se le agregan los padecimientos de hambre, situaciones que llevaban a los internos a fugarse. ${ }^{28}$

\footnotetext{
León Gómez, La ciudad del dolor, 140-141.

León Gómez, La ciudad del dolor, 30.

León Gómez, La ciudad del dolor, 32.

28 Comenta sobre compañeros que se iban a mendigar a poblaciones que no eran tan hostiles con los leprosos: "Huyeron de su cárcel vitalicia porque les debían ocho de las miserabilísimas raciones que la Nación les da para vivir, en cambio de todos los derechos, todas las libertades, todos los bienes y todas las garantías que les quita para siempre. Huyeron, porque además del alimento, les faltaba el agua indispensable aun para las más premiosas necesidades. Huyeron, porque careciendo de todo recurso para sostenerse, no tienen obligación de dejarse morir de hambre". León Gómez, La ciudad del dolor, 194.
} 
Como era de esperarse de un personaje con semejante compromiso político, León Gómez no se quedó en la autocontemplación. Su libro empezó a convertirse en un análisis de Derecho Penal y Constitucional aplicado a su drama. En el capítulo XII de la segunda parte, llamado "Una dictadura incrustada en una República", se pregunta qué es la dictadura y afirma: "Eso y no otra cosa es la pintoresca y populosa, pero atormentada Ciudad del Dolor. Allí todo es anómalo, todo es extraño, todo es arbitrario". ${ }^{29}$

La Constitución no era un referente válido para los internos, pues el carcelero era el amo y señor. Una voluntad que no se sometía a la Constitución; un verdugo con poder, pero sin autorización. La verificación de esta tierra-de-nadie llevó a León Gómez a emprender el activismo que le fuera posible a favor de sus colegas de dolor. Cuenta en el capítulo "Arando en el mar" que Sur América, el periódico que había fundado, ya no solo se encargaría de defender a la República y la unión hispanoamericana, sino también de la campaña en pro "de los desgraciados habitantes de los leprosorios". Dice:

Así como en otras épocas, sin descuidar aquellos grandes ideales, luchó tenazmente contra la dictadura, los monopolios, el amordazamiento de la prensa y toda clase de abusos e ilegalidades y en pro de los principios republicanos, las libertades ciudadanas, la instrucción pública, los derechos del pueblo, la paz, el orden y el bien general, así quiso hacer también algo por los infelices. ${ }^{30}$

Esos infelices siguieron siendo confinados de manera forzosa hasta 1961, año en el que se levantó la política de aislamiento en los lazaretos de Agua de Dios, Contratación y Caño de Loro. ${ }^{31}$

En su lucha y en el sitio al que le dedicaría su última obra, murió Adolfo León Gómez el 9 de junio de 1927; dejó un enorme legado y testimonio de un gran dolor. Su poema "Las noches de Agua de Dios" nos transmite, sin discursos fríamente hilvanados, la pasión del confinado:

Los que en ensueños de amor hacen de risas derroche no saben lo que es la noche de la Ciudad del Dolor.

\footnotetext{
León Gómez, La ciudad del dolor, 157.

León Gómez, La ciudad del dolor, 135.

Sotomayor Tribín, "Historia de la lepra en Colombia".
} 
Si lo supieran lloraran con tan hondo desconsuelo, que las estrellas del cielo por no llorar, pestañaran.

Tristezas de último adiós con auras de cementerio envuelven en su misterio las noches de Agua de Dios.

Desengaños y reproches y recuerdos y amarguras, llenan de sombras oscuras la soledad de esas noches.

Cenizas llevando van, entre sus alas sombrías, de las muertes alegrías que ya nunca volverán.

Vienen trayendo el gemido del lejano y triste hogar de donde quitó el pesar el suave calor del nido.

¡Oh! ¡Sueños, pasad, pasad como ha pasado la vida! ¡Con la esperanza perdida, recuerdos volad, volad!

¡Volad, porque no resiste del recuerdo los rigores el corazón sin amores que está tan solo y tan triste! ${ }^{32}$

32 León Gómez, La ciudad del dolor, 148-149. Estos versos fueron musicalizados por Carlos Vieco Ortíz, en 1924. Puede escucharse la versión interpretada por el conjunto Los Médicos en https://www.youtube.com/ watch?v=MI0AJI9d4v4 


\section{III}

Lo que se ha querido mostrar en este trabajo es la vinculación personal, la fría capacidad descriptiva del encierro y su inteligencia para valorar los fenómenos humanos que implican el presidio. Esto es lo que hace del estudio de su vida y obra un paso obligado hacia la reconstrucción del pensamiento criminológico colombiano. Es quizá el precursor. No solo observó la realidad del presidio en una época de guerra y biopoder en Colombia: también nos traslada a la psiquis y al drama existencial del que, sin haber hecho tanto para merecerlo, preso solo espera su "Última luz":

Le ofrecí mi pasión y fue perdida aquella de mi amor sincera carta. Con sus ojos que piensan, errabundos, sin ver mi pobre carta, la miraba.

Le dieron la noticia de mi ausencia.

No pareció que le importase nada. ¡Ni un suspiro lanzó por el que siempre soñó con ella en extranjera playa!

Llegó á su puerta el eco de mis triunfos, llegó mi nombre en brazos de la fama. ¡Tanto caso hizo de él, como las olas de humilde brisa que sobre ellas pasa!

Años más tarde se escuchó la queja de un pobre corazón que agonizaba... Mis suspiros llegaron á su oído, mas no alcanzaron á llegar á su alma.

Supo la enormidad de mis dolores, supo la inmensidad de mi desgracia. Se conmovió como las negras rocas al gemido del viento en la borrasca...

Le dieron la noticia de mi muerte. Pareció recordar... ¡Oh! ¡Despertaban mis versos, mis suspiros y mis glorias y mi infinito amor sin esperanza! 
Por la primera vez, mojado en llanto, en ese mudo hablar de su mirada, apareció mi nombre... ¡Oh muerte! ¡Oh muerte!

¡Sólo tú arrancas para mí una lágrima! ${ }^{33}$

\section{Referencias}

Bushnell, David. Colombia, una Nación a pesar de sí misma. Traducido por Claudia Montilla. Bogotá: Planeta, 2007.

García Núñez, Luis Fernando. "Anécdotas y dramas: los sufrimientosde Adolfo León Gómez". Credencial Historia, núm. 219 (2008), http://www.banrepcultural.org/blaavirtual/ revistas/credencial/marzo2008/adolfoleon.htm

León Gómez, Adolfo. Secretos del Panóptico. Bogotá: Imprenta M. Rivas, 1905.

León Gómez, Adolfo. La ciudad del dolor: ecos del presidio de inocentes. Bogotá: Imprenta M. Rivas, 1923.

Molano Jimeno, Alfredo. "Adolfo León Gómez, el desterrado (1858-1927)". Tesis de pregrado, Pontificia Universidad Javeriana, 2015.

Obregón, Diana. Batallas contra la lepra: Estado, Medicina y ciencia en Colombia. Medellín: Banco de la República-Eafit, 2002.

Ocampo López, Javier. Colombia en sus ideas. T. II. Bogotá: Universidad Central, 1999.

Otero Ruíz, Efraím. "Adolfo León Gómez (1858-1927), republicano, poeta y mártir". Boletín de Historia y Antigüedades XCIX, núm. 855 (2012): 353-376.

Rivas Groot, José María, comp. La lira nueva. Bogotá: Instituto Caro y Cuervo, 1993.

Silva García, Germán. Criminología: construcciones sociales e innovaciones teóricas. Bogotá: Instituto Latinoamericano de Altos Estudios, 2011.

Sotomayor Tribín, Hugo Armando. "Historia de la lepra en Colombia". http://www.sanatorioaguadedios.gov.co/documentos/histolepracolombia.pdf (acceso febrero 25, 2012).

33 Rivas Groot, La lira nueva, 175. 